\title{
Relative performance of different concentrations of mint (Mentha longifolia L.) against Tribolium castaneum (Coleoptera: Tenebrionidae) in wheat
}

\author{
Muneer Ahmed Bhatti ${ }^{1}$, Lubna Bashir Rajput ${ }^{1}$, Arfan Ahmed Gilal ${ }^{1 *}$, \\ Jam Ghulam Mustafa Sahito ${ }^{2}$, Muhammad Umar Brohi ${ }^{1}$ and Shahid \\ Ali Chandio ${ }^{1}$ \\ 1. Department of Entomology, Faculty of Crop Protection, Sindh Agriculture University, Tandojam-Pakistan \\ 2. Department of Agriculture and Agribusiness Management University of Karachi-Pakistan \\ *Corresponding author's email: aagilal@sau.edu.pk \\ Citation \\ Muneer Ahmed Bhatti, Lubna Bashir Rajput, Arfan Ahmed Gilal, Jam Ghulam Mustafa Sahito, Muhammad \\ Umar Brohi and Shahid Ali Chandio. Relative performance of different concentrations of mint (Mentha \\ longifolia L.) against Tribolium castaneum (Coleoptera: Tenebrionidae) in wheat. Pure and Applied Biology. \\ Vol. 9, Issue 4, pp2470-2475. http://dx.doi.org/10.19045/bspab.2020.90262

\begin{tabular}{|c|c|c|c|}
\hline Received: 06/04/2020 & Revised: 01/07/2020 & Accepted: 06/07/2020 & Online First: $28 / 07 / 2020$ \\
\hline
\end{tabular}

\section{Abstract}

The experiment on effectiveness of various concentrations of mint leaves Mentha longifolia $\mathrm{L}$. was conducted at Sindh Agriculture University, Tando Jam. Mint powder was applied at $2.00 \%, 1.50 \%, 1.00 \%$ and $0.50 \%$ concentrations in $200 \mathrm{gm}$ of wheat grains (variety TD-1) in plastic jars against Triboleum castaneum. The observations on efficacy of different concentrations as mortality of beetles was recorded after 24 hours, 48 hours and 7 days, whereas, population fluctuation was observed at monthly intervals for three months. Weight loss was also noted at the end of experiment. Although, no significant mortality of T. castaneum was recorded in any treatment, a rise in mortality was recorded after 48 hours of application as significantly higher mortality was observed in $2 \%$ mint concentration $(4.33 \pm 0.33)$, followed by $1.5 \%(2.67 \pm 0.33), 1 \%(1.33 \pm 0.33)$ and $0.5 \%(1.00 \pm 0.00$. Overall at the end of week, the highest $(66.70 \%)$ and lowest $(26.70 \%)$ percentage mortality of $T$. castaneum was recorded in $2 \%$ and $0.50 \%$ mint concentrations, respectively. The population fluctuation of $T$. castaneum also showed that at the end of third month, control showed the highest population $(45.67 \pm 2.91$ beetles) of beetles, whereas, $2.00 \%$ mint concentration treatment exhibited lowest population of beetles (16.33 \pm 0.88$)$. The maximum overall (50.33grams or $25.17 \%)$ and grain $(63.00$ grams or $31.50 \%$ ) weight loss was recorded in control, whereas, $2.00 \%$ mint concentration treatment exhibited overall (19.00/9.50\%) and grains $(24.67 / 12.33 \%)$ weight loss. Thus, it is suggested that $2.00 \%$ mint concentration should be included as protectant in store grains especially wheat against $T$. castaneum.

Keywords: Mint; Mortality; Population; Tribolium castenium; Wheat

Introduction

Wheat (Triticum aestivum) holds a key role among all the cereals to fulfill the dietary requirements of the peoples of the world especially in Pakistan [1]. It contributed about $8.9 \%$ value addition in agriculture 
and $1.6 \%$ of gross development production (GDP) in Pakistan. During 2018-19, the total cultivated area of this crop was 8,740 thousand hectares showing a decline of about 0.6 percent compared to 8,797 thousand hectares during same period last year. The main reasons of decline are water shortages, delayed and prolonged sugarcane crushing season, fog and smog in the country [2]. In addition, after harvesting, the stored wheat is severally infested by different types of insect pests which degrade the quality and the quantity of the grain. The infested seeds are not suitable for consumption as well as for sowing purpose. In Pakistan, wheat grains are attacked by more than 23 insect species during storage; among them, 10 species are known to be very serious [3]. The major stored grain insect pests attacking on stored wheat include Sitophilus granarius L., Rhyzopertha dominica Fabr, Tribolium castaneum Herbst., Prostephanus truncates Horn, Sitophilus oryzae L., Sitotroga cerelella Olivier and Plodia interpunctella Hubner [4].

Red flour beetle, Tribloium castaneum Herbst (Coeloptera: Tenebrionidae) is considered as a destructive insect pest of wheat [5]. Tribloium castaneum cause huge damage to stored grains. It is the most common pest of wheat flour; however, it also infests the quality and quantity of the pulses and other stored cereal foods, dried fruits, such as pasta, cornflake, beans, nuts, biscuit, etc. [6]. The pest is found throughout the world but use protected places having heat conditions to survive extreme winters [7]. Both, larvae and adults cause damage to stored product and pass their whole life outside of the host [8].

Mostly, warehouse managers depend upon synthetic pesticides for the management of T. castaneum. However, high doses of pesticides have not only contaminated the stored products but also cause severe adverse environmental and health hazards [9]. Moreover, high pesticides application has depleted ozone layer; induce pesticide residues in food chains along with various other problems [10]. During the recent years, botanicals are used as insecticides that can be obtain from natural products. These botanicals not only kill the pests but also protect our society from chemical pesticides and also protect the natural enemies [11]. Various kinds of botanicals are used as insecticides against store grain products. The stored product pests exhibit different levels of sensitivity or tolerance to plant extracts, a wide screening of these substances has been carried out to widen the available tools against these harmful organisms with promising results [12]. Among botanicals, mint extracts are used on wide scale to manage the populations of stored product pests throughout the world. The genus Mentha belongs to the family Lamiaceae that can be used in the pest management programs because of its insecticidal properties [13]. Mint oil is known to contain various monoterpenoids with piperitone, pulegone, $\alpha$-limonene, piperitone oxide, $\beta$-caryophyllene, 1-8Cineole, piperitenone, carvone, menthone, as major chemical components [14]. However, there have been some differences in the ingredients from various countries and a chemo-geographical variation has been observed in essential oil composition of this species [15]. Although, mint has shown many insecticidal activities, but studies on its effect in the management of $T$. castaneum in stored wheat are lacking. Therefore, this study was conducted to evaluate effectiveness of various concentrations of mint powder against $T$. castaneum in wheat.

\section{Materials and methods Study location}

The experiment was carried out in the Stored Grain Research Laboratory, Department of Entomology, Sindh Agriculture University, Tandojam during the year 2017-2018.

\section{Insect collection and rearing}

The culture of $T$. castaneum was obtained from already maintained culture of the laboratory that was reared on the pure 
wheat grains under controlled temperature $\left(28 \pm 2^{\circ} \mathrm{C}\right)$ and $75 \pm 5 \%$ R.H

Selection of plant material and extract preparation

Mint (Mentha longifolia L.) leaves were collected from the local market of Tandojam, thoroughly washed and air dried under shade. The dried plant materials were then grinded by using electric blender and sieve by muslin cloth. The obtained fine powder was the stored in airtight plastic bottles to restore their freshness before usage in the experiment.

Experimental outline, data collection and analysis

Powder of mint leaves was applied at different concentrations i.e., $2 \%, 1.5 \%, 1 \%$ and $0.5 \%$ in $200 \mathrm{gm}$ of wheat grain (Variety TD-1) in individual glass jars. The powder was shacked thoroughly in seed for about 3 minutes to create a homogenous mixture. In each container, ten pairs of freshly emerged adults of $T$. castaneum were released. The jars were covered with muslin cloth and tighten with elastic rubber band to restrict the beetles inside the jars. Experiment was laid down in a Completely Randomized Design where each treatment was replicated three times. The data on efficacy of different concentrations of mint to cause mortality of $T$. castaneum was recorded after 24 hours, 48 hours and 7 days of their application, whereas, population fluctuation of $T$. castaneum was observed at monthly intervals for three months. At the end of experiment, overall and grain weight loss was recorded using the following formula:

$\%$ damage $=[($ Original weight - Final Weight)/ Original Weight] $* 100$

The obtained data was analyzed using Analysis of Variance whereas, the means with significant differences were compared using the Least Square Difference (LSD) at 0.5 probability level. All the analysis was done using STATISTIX computer software 8.1 .

\section{Results}

Effect of different concentrations of mint on mortality of $T$. castaneum in wheat at different intervals

The mortality rate of $T$. castaneum in wheat due to the application of different concentrations of mint i.e., $2 \%, 1.5 \%, 1 \%$ and $0.5 \%$ at various time intervals (24 hours, 48 hours and 1 week) is given in (Table 1). The results indicated that all mint concentrations caused mortality immediately after their application. However, after 24 hours of application, a non-significant difference $(\mathrm{F}=3.00, \mathrm{P}=$ 0.0723 ) was recorded among various mint concentrations to elicit mortality of $T$. castaneum. After 24 hours, the highest mortality was recorded in $2 \%$ concentration (2.00 \pm 0.58 beetles), followed by $1.5 \%$ concentration ( $1.00 \pm 0.58$ beetles), whereas, no mortality was recorded in control.

Table 1. Effect of different mint concentrations on mortality of $T$. castaneum in wheat under laboratory conditions

\begin{tabular}{|c|c|c|c|c|c|}
\hline \multirow{2}{*}{$\begin{array}{c}\text { Mint } \\
\text { concentration }\end{array}$} & \multicolumn{4}{|c|}{ Population } & $\begin{array}{c}\text { Overall Mortality } \\
\text { \% after week }\end{array}$ \\
\cline { 2 - 5 } & Pretreatment & $\mathbf{2 4}$ hours & $\mathbf{4 8}$ hours & 1 Week & $26.70 \%$ \\
\hline $0.5 \%$ & 20 & $0.67 \pm 0.33 \mathrm{~b}$ & $1.00 \pm 0.00 \mathrm{c}$ & $2.67 \pm 0.33 \mathrm{c}$ & $33.30 \%$ \\
\hline $1 \%$ & 20 & $0.67 \pm 0.33 \mathrm{~b}$ & $1.33 \pm 0.33 \mathrm{c}$ & $3.33 \pm 0.67 \mathrm{bc}$ & $46.70 \%$ \\
\hline $1.5 \%$ & 20 & $1.00 \pm 0.58 \mathrm{ab}$ & $2.67 \pm 0.33 \mathrm{~b}$ & $4.67 \pm 0.67 \mathrm{~b}$ & $6.70 \%$ \\
\hline $2 \%$ & 20 & $2.00 \pm 0.58 \mathrm{a}$ & $4.33 \pm 0.33 \mathrm{a}$ & $6.67 \pm 0.88 \mathrm{a}$ & $66.70 \%$ \\
\hline Control & 20 & 0 & 0 & 0 & $0.00 \%$ \\
\hline
\end{tabular}

*Means followed by the same letters in same columns are not significantly different (LSD, P < 0.05)

An equal mortality $(0.67 \pm 0.33$ beetles $)$ of T. castaneum was recorded in $1 \%$ and 0.5 $\%$ concentrations. A rise in mortality was recorded after 48 hours of application as significantly higher $(\mathrm{F}=42.2, \mathrm{P}<0.001)$ mortality of beetles was observed in $2 \%$ concentration $(4.33 \pm 0.33)$, followed by 1.5 $\%(2.67 \pm 0.33), 1 \%(1.33 \pm 0.33)$ and $0.5 \%$ $(1.00 \pm 0.00)$ concentrations. After one week of application, mortality of $T$. castaneum 
observed in $2 \%, 1.5 \%, 1 \%$ and $0.5 \%$ was $6.67 \pm 0.88, \quad 4.67 \pm 0.67, \quad 3.33 \pm 0.67$ and $2.67 \pm 0.33$, respectively. Therefore, a significant difference $(\mathrm{F}=17.1, \mathrm{P}<0.0002)$ was recorded in the mortality of $T$. castaneum due to the application of various mint concentrations.

Overall at the end of week, the highest and lowest percentage mortality of $T$. castaneum was recorded in $2 \%(66.70 \%)$ and $0.5 \%(26.70 \%)$ mint concentrations, respectively. No beetle mortality was recorded in control treatment (Table 1).

Effect of mint concentrations on the population development of $T$. castaneum Results for the population fluctuation of red flour beetle in wheat treated with various mint concentrations are given in (Table $2 \&$ Fig. 1). A highly significant difference in the population development of $T$. castaneum was recorded in wheat treated with various concentrations of mint throughout three months of observations. After one month, the highest mean population of red flour beetle was recorded in control $(20.67 \pm 1.76$ beetles), followed by $0.5 \% \quad(15.67 \pm 1.20) \quad 1 \% \quad(14.33 \pm 1.45$ beetles) $1.5 \%(9.00 \pm 0.58$ beetles) and $2 \%$ $(5.67 \pm 0.88)$. In the following month, a steady growth was observed in all the treatments excluding control, where a rapid growth was recorded in control. Accordingly, at the end of month three, the highest population of $T$. castaneum was recorded in control $(45.67 \pm 2.91$ beetles), whereas, the beetle population observed in $0.5 \% 1 \%$, and $2 \%$ concentrations was (31.33 \pm 2.33 beetles) ( $29.00 \pm 4.16$ beetles) and ( $21.00 \pm 1.73$ beetles) respectively.

Table 2. Weight loss of wheat mixed with different mint concentrations by $T$. castaneum under laboratory conditions

\begin{tabular}{|c|c|c|c|c|c|}
\hline \multirow{2}{*}{ Concentration } & \multicolumn{3}{|c|}{ Weight (Grams) } & \multicolumn{2}{c|}{ Weight loss (grams / \%) } \\
\cline { 2 - 6 } & Initial & Overall Final & Grain & Overall & Grain \\
\hline $0.5 \%$ & 200 & $159.00 \pm 1.15 \mathrm{c}$ & $150.00 \pm 1.15 \mathrm{c}$ & $41.00(20.50 \%)$ & $50.00(25.00 \%)$ \\
\hline $1 \%$ & 200 & $169.33 \pm 0.88 \mathrm{~b}$ & $162.33 \pm 1.45 \mathrm{~b}$ & $30.67(15.33 \%)$ & $37.67(18.33 \%)$ \\
\hline $1.5 \%$ & 200 & $177.00 \pm 1.53 \mathrm{a}$ & $170.33 \pm 1.45 \mathrm{a}$ & $23.00(11.50 \%)$ & $29.67(14.83 \%)$ \\
\hline $2 \%$ & 200 & $181.00 \pm 4.62 \mathrm{a}$ & $175.33 \pm 3.48 \mathrm{a}$ & $19.00(9.50 \%)$ & $24.67(12.33 \%)$ \\
\hline Control & 200 & $149.67 \pm 0.88 \mathrm{~d}$ & $137.00 \pm 2.65 \mathrm{~d}$ & $50.33(25.17 \%)$ & $63.00(31.50 \%)$ \\
\hline
\end{tabular}

*Means followed by the same letters in same columns are not significantly different (LSD, P < 0.05)

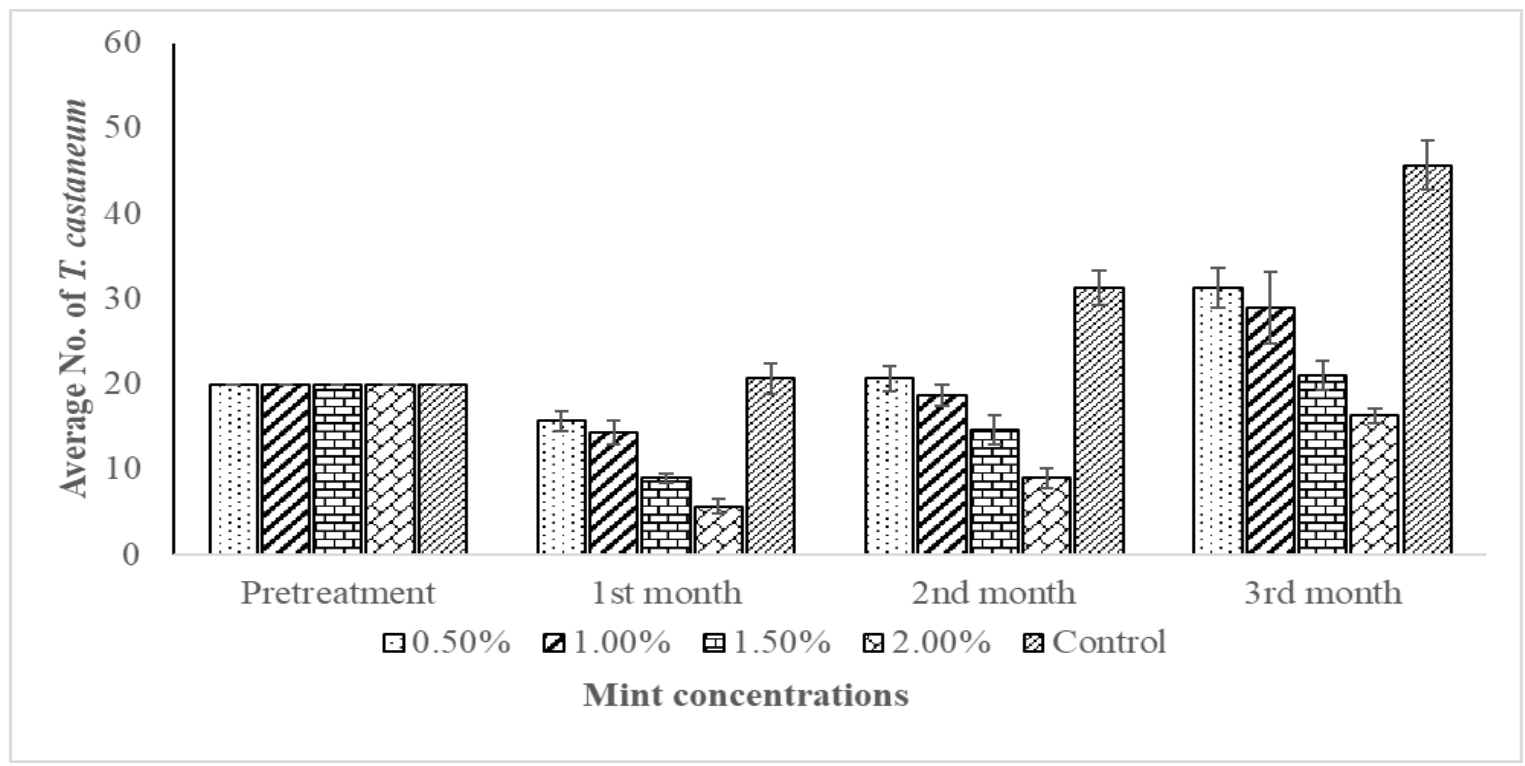

Figure 1. Effect of different mint concentrations on the population development of $T$. castaneum in wheat under laboratory conditions 


\section{Weight loss of wheat mixed with different mint concentrations by $T$. castaneum}

The weight loss in wheat due to the feeding of $T$. castaneum under the effect of various mint concentrations is given in (Table 2). Results indicated that overall weight loss in various concentration differs significantly $(\mathrm{F}=31.3, \mathrm{P}$ $<0.001)$ due to feeding of $T$. castaneum as significantly the highest weight loss at the end of experiment was observed in control (50.33 grams or $5.17 \%)$, followed by $0.5 \%$ (41.00 grams or $20.50 \%$ ), $1.00 \%$ (30.67 grams or $15.33 \%$ ) concentrations. Overall, the lowest weight loss was recorded in wheat treated with $2 \%$ mint concentration (19.00 grams or $9.50 \%$ ). In continuation with overall weight loss, the highest and lowest grain weight loss of wheat due to infestation of $T$. castaneum was also recorded in control (63.00 grams or $31.50 \%$ ) and $2 \%$ mint concentration (24.67 grams or $12.33 \%$ ) treatment. Thus, the various concentrations showed a highly significant $(\mathrm{F}=$ $68.90, \mathrm{P}<0.001$ ) difference in grain weight loss occurred due to the infestation of $T$. castaneum on wheat mixed with different mint concentrations.

\section{Discussion}

It has been reported that many plants have insecticidal activities against many noxious pests of crops and stored products. Similarly, this study indicated the significant effect of different mint concentrations to cause mortality and effect population development of $T$. castenium in wheat. Accordingly, the highest mortality was recorded in $2.00 \%$ concentration, whereas, the lowest population was also recorded in $2.00 \%$ concentration followed by $1.50 \%$ concentration. Furthermore, the highest and the lowest overall and grain weight loss was recorded in control and $2.00 \%$ concentration, respectively. The efficacy of mint plant extracts in the management of population of $T$. castenium has previously been also reported. Khani and Asghari [16] studies while evaluating the toxic volatile performance of essential oils obtained from leaves of $M$. longifolia, Pulicaria gnaphalodes, and Achilles wilhelmsii against Callasobruchus maculatus and $T$. castaneum confirmed that in comparison to $T$. castaneum, C. maculatus were found to be more susceptible against the treatments used in the study. They also reported that oils of $A$. wilhelmsii and $M$. longifolia showed relatively similar and more toxicity against $T$. castaneum than oil of $P$. gnaphalodes. Along with mint, various oil extractions of sesame, (Sesamum indicium), coconut (Coccus nucifera), rocket seed (Eurica sativa) and mustard (Brassica campestris) have also shown insecticidal properties against $T$. castaneum in wheat [17]. Although, relatively less population of beetles was recorded in wheat treated with above mentioned treatments than control, with minimum fecundity recorded in rocket seed treated wheat [17]. The fumigant and repellent properties of pennyroyal (Mentha pulegium L.) aerial parts and castor (Ricinus communis L.) stems essential oils were tested against Lasioderma serricorne and T. castaneum. The tested plant oils showed relatively strong fumigant properties against $R$. communis and repellent effects against $T$. castaneum [18]. Many other studies also showed promising impact of not only various mint species but also other plants in reducing the population development and thus, damage to stored grains, especially wheat [19-21].

\section{Conclusion}

It has been concluded that all mint concentrations used caused mortality of the targeted $T$. castaneum in wheat, as mortality increased as mint concentrations increased. Thus, 2\% concentrations showed maximum mortality and least development of beetles in wheat, thus, minimum weight loss. Control exhibited maximum growth and weight loss due to the feeding of T. castaneum. Therefore, addition of mint at $2 \%$ concentration in wheat is suggested to lower the population development of beetles and thus, weight loss to wheat.

\section{Authors' contributions}

Conceived and designed the experiments: AA Ahmed \& L Bashir, Performed the experiments: M Ahmed, Analyzed the data: JGM Sahito, Contributed reagents/ materials/ analysis tools: MU Brohi \& SA Chandio, Wrote the paper: MU Brohi \& AA Gilal

\section{References}

1. Iqbal N, Bakhsh K, Maqbool A \& Ahmad AS (2005). Use of the ARIMA model for forecasting wheat area and production in Pakistan. J Agric Soc Sci 1(2): 120-122.

2. GOP (2019). Area and production of other major kharif and rabi crops. Economic Survey of Pakistan, Ministry Government of Pakistan, Islamabad, Food and Agriculture. Federal Bureau of Statistics, pp 22. 
3. Lohar MK (2001). Pest of stored grains and their control. In: Textbook of applied entomology. Kashif Publication, Hyderabad, Pakistan. pp 147-167.

4. Ileke K \& Bulus D (2011). Response of lesser grain borer, Rhizopertha dominica (Fabr.) (Coleoptera: Bostrichidae) to powders and extracts of Azadirachta indica and Piper guineense seeds. Jordan J Biol Sci 5(5): 315-320.

5. Sarwar M (2013). Development and boosting of integrated insect pest management in stored grains. J Agric Allied Sci 2 (4): 16-20.

6. Tripathi AK (2018). Pests of Stored Grains. In Pests and Their Management. Springer, Singapore. pp 311-359.

7. Tripathi AK, Pragapati V, Aggarwal KK \& Kumar S (2001). Toxicity feeding deterrence and effect of activity of 1,8 , cinecola from Artemisia unnica on progeny production of Tribolium castaneum (Coleoptera: Tenebrionidae). J Eco Entomol 94: 979-983.

8. Karunakaran C, Jayas DS \& White NDG (2004). Identification of wheat kernels damaged by the red flour beetle using X-ray images. Biosyst Eng 87(3): 267-274.

9. Kiran S \& Prakash B (2015). Assessment of toxicity, antifeedant activity, and biochemical responses in stored-grain insects exposed to lethal and sublethal doses of Gaultheria procumbens L. essential oil. $J$ Agric Food Chem 63: 10518-10524.

10. Isman MB (2006). Botanical insecticides, deterrents, and repellents in modern agriculture and an increasingly regulated world. Ann Rev Entomol 5(1): 45-66.

11. Guleria S \& Tiku AK (2009). Botanicals in pest management: current status and future perspectives. In: Peshin R, Dhawan AK, editors. Integrated pest management: innovation-development process. Springer, Netherlands, pp 317-329.

12. Athanassiou CG, Rani PU \& Kavallieratos NG (2014). The use of plant extracts for stored product protection. In: Singh D, editor. Advances in Plant Biopesticides. Springer, India. pp 131-147.

13. Saljoqi AUR, Afridi MK \& Khan SA (2006). Effects of six plant extracts on rice weevil Sitophilus oryzae L. in the stored wheat grains. J Agric Biol Sci 1(4): 19906145.

14. Koul O, Walia S \& Dhaliwal GS (2008). Essential oils as green pesticides: potential and constraints. Biopesticides Int 4(1): 6384.

15. Oyedeji AO \& Afolayan AJ (2006). Chemical composition and antibacterial activity of the essential oil isolated from South African Mentha longifolia (L.) $J$ Essential Oil Res 18: 57-60.

16. Khani A \& Asghari J (2012). Insecticide activity of essential oils of Mentha longifolia, Pulicaria gnaphalodes and Achillea wilhelmsii against two stored product pests, the flour beetle, Tribolium castaneum, and the cowpea weevil, Callosobruchus maculatus. J Ins Sci 12(1): 1-10.

17. Khanzada H, Sarwar M \& Lohar MK (2015). Repellence activity of plant oils against red flour beetle Tribolium castaneum (Herbst) (Coleoptera: Tenebrionidae) in wheat. Inter J Anim Biol 1: 86-92.

18. Salem N, Bachrouch O, Sriti J, Msaada K, Khammassi S, Hammami M, Selmi S, Boushih E, Koorani S, Abderraba M \& Marzouk B (2017). Fumigant and repellent potentials of Ricinus communis and Mentha pulegium essential oils against Tribolium castaneum and Lasioderma serricorne. Inter J Food Prop 20(3): 28992913.

19. Heydarzade A, Valizadegan O, Negahban M \& Mehrkhou F (2019). Efficacy of Mentha spicata and Mentha pulegium essential oil nanoformulation on mortality and physiology of Tribolium castaneum (Col.: Tenebrionidae). J Crop Prot 8(4): 501-520.

20. Nath R, Singh G \& Deep G (2019). Efficacy of some botanical extracts against Tribolium castaneum: Coleoptera (Tenebrionidae). Plant Cell Biotech Mol Biol 20(15\&16): 660-666.

21. Pang X, Feng YX, Qi XJ, Wang Y, Almaz B, Xi C \& Du SS (2020). Toxicity and repellent activity of essential oil from Mentha piperita Linn. Leaves and its major monoterpenoids against three stored product insects. Environ Sci Poll Res 27(7): 7618-7627. 